\title{
Perfil das ocorrências de politrauma em condutores motociclísticos atendidos pelo SAMU de Teresina-PI
}

\author{
Profile of multiple trauma occurrences in motorcycle drivers attended by the SAMU of Teresina-PI \\ Perfil de ocurrencias de politraumatismos en conductores de motocicletas \\ atendidos por el SAMU de Teresina-PI
}

\author{
Dinah Sá Rezende Neta', Anne Karolinne e Silva Alves', \\ Gustavo de Moura Leão', André Alves de Araújo" \\ ' Faculdade Integral Diferencial, Curso de Graduação em Enfermagem. Teresina-Pl, Brasil. \\ "Secretaria Municipal de Saúde, Estratégia Saúde da Família. Barras-PI, Brasil.
}

Submissão: 26-01-2011

Aprovação: 31-01-2013

\section{RESUMO}

O estudo objetivou investigar o perfil das ocorrências de politrauma em condutores motociclísticos atendidos pelo Serviço de Atendimento Móvel de Urgência de Teresina-PI. Realizou-se um estudo quantitativo e documental, mediante informações colhidas das fichas de atendimento desse serviço no ano de 2009. A coleta dos dados ocorreu nos meses de fevereiro e março do ano de 2010. As motocicletas envolveram-se em $84 \%$ dos acidentes, sendo os homens de 21 a 30 anos os mais acometidos. O final de semana e a zona urbana registraram mais casos. Destacaram-se os traumas musculoesqueléticos (59\%). As vítimas alcoolizadas totalizaram 12\%. A mortalidade correspondeu a 1\%. Conclui-se ser imprescindível a adoção de medidas socioeducativas que garantam o comportamento adequado dos indivíduos no trânsito.

Descritores: Acidentes de Trânsito; Perfil de Saúde; Serviços Médicos de Emergência; Prevenção de Acidentes.

\begin{abstract}
The study aimed to investigate the profile of polytrauma occurrences in motorcycle drivers Service at Mobile Emergency Care of the county of Teresina-PI. We conducted a quantitative and documentary study, with information gathered through the medical records of that service, in 2009. Data collection was conducted from February to March of 2010. The motorcycles were involved in $84 \%$ of accidents, and men of 21 to 30 years old were the most affected. The weekend and the urban area recorded more cases. The musculoskeletal trauma (59\%) stood out. The alcoholic victims numbered $12 \%$. Mortality was of $1 \%$. We conclude that it is essential to adopt educational measures to ensure the proper behavior of individuals in transit.
\end{abstract}

Key words: Traffic Accident; Health Profile; Emergency Medical Service; Accidents Prevention.

\section{RESUMEN}

El objetivo del estudio fue investigar el perfil de ocurrencias de politraumatismos en conductores de motocicleta atendidos por el Servicio de Atención Móvil de Urgencia de Teresina-PI. Se realizó un estudio cuantitativo y documental, con la información siendo recopilada a través de las historias clínicas de este servicio en 2009. La recolección de datos se Ilevó a cabo en febrero y marzo de 2010. Las motocicletas participaron en 84\% de los accidentes, y los hombres de 21 a 30 años fueron los más afectados. El fin de semana y el área urbana registraron más casos. Lo más destacado fue el trauma osteomuscular (59\%). Las víctimas alcohólicas ascendieron a 12\%. La mortalidad fue del 1\%. Llega-se a la conclusión de que es indispensable adoptar medidas educativas para asegurar el buen comportamiento de los individuos en tránsito.

Palabras clave: Accidentes de Tránsito; Perfil de Salud; Servicios Médicos de Urgencia; Prevención de Accidentes. 


\section{INTRODUÇÃO}

As mudanças sociais, políticas, econômicas, o crescimento urbano e o desenvolvimento da indústria automobilística trouxeram graves problemas de Saúde Pública ao Brasil, como os acidentes e violências de trânsito, os homicídios, os autoextermínios e os acidentes em geral, que são considerados a grande epidemia do século $X X^{(1)}$. A ênfase aqui, no entanto, será dada aos traumas decorrentes de acidentes de trânsito envolvendo motocicletas, tendo em vista o seu forte impacto na elevação gradual dos índices de morbimortalidade na população.

Os Acidentes de Trânsito (ATs) motociclísticos estão se tornando cada dia mais comuns, consolidando-se como a terceira causa de obituário mundial, antecedida apenas pelas doenças cardiovasculares e neoplásicas. Diante dessa situação, tornou-se consenso mundial devotar mais atenção ao Atendimento Pré-Hospitalar (APH), na tentativa de minimizar a morbimortalidade no atendimento ao traumatizado ${ }^{(2)}$.

O atendimento inicial com avaliação primária, estabilização e transporte da vítima de agravos de trânsito até um centro de melhor referência para dar continuidade ao serviço de emergência minimiza a ocorrência de lesões decorrentes de um atendimento ineficiente no local (1). Além disso, gera informações para o aprimoramento de políticas públicas mais efetivas no tocante às ações de prevenção das doenças/agravos, educação, proteção e recuperação da saúde e reabilitação dos indivíduos ${ }^{(3)}$.

Os acidentes motociclísticos estão relacionados a uma cadeia de causalidade. Para se conhecer em maior detalhamento esse agravo, o primeiro passo é a descrição exata e minuciosa de como ele acontece. Assim, torna-se fundamental obter o maior número de informações possíveis sobre esses acontecimentos, a fim de reunir, sistematicamente, dados sobre a extensão, características e consequências desse problema de saúde pública, dimensionando seu impacto na vida das vítimas ${ }^{(4)}$. O entendimento dos fatores relacionados aos acidentes motociclísticos tem evidenciado a necessidade de disponibilizar recursos para a prevenção, com atuação no direcionamento das intervenções conforme os fatores de risco específicos da população alvo ${ }^{(5)}$.

Assim a realização deste estudo se justifica pela preocupação com o aumento do número de vítimas dos acidentes motociclísticos. A elevação desse evento exige mais informações sobre a população envolvida, as circunstâncias do acidente e os fatores de risco associados para fundamentar a tomada de decisões das autoridades para problemas no trânsito, no sentido de minimizar tanto a frequência de acidentes como suas drásticas consequências. Por fim, os resultados poderão estimular - e subsidiar - pesquisas futuras acerca do tema. Essas pesquisas certamente contribuirão para a formulação de estratégias de enfrentamento desse agravo.

Em face do exposto, o presente trabalho teve como objetivo investigar o perfil das ocorrências de politrauma em condutores motociclísticos atendidos pelo SAMU de Teresina no ano de 2009.

\section{METODOLOGIA}

Trata-se de um estudo documental, descritivo, com abordagem quantitativa. A escolha do método justifica-se, por permitir descrever os aspectos do fenômeno estudado, identificando as prováveis causas, determinando a frequência e categorizando as informações colhidas dos documentos analisados $^{(6)}$. Com a aplicação do método quantitativo, tornou-se possível gerar dados estatísticos por meio da mensuração da população analisada que compartilhou as características do estudo ${ }^{(7)}$.

O universo da população analisada foi constituído por 3.829 fichas de atendimento do SAMU a vítimas politraumatizadas por acidentes motociclísticos, fichas geradas pelas Unidades de Suporte Básicas e Avançadas no ano de 2009. Os critérios de inclusão relacionam-se aos casos de acidentes motociclísticos com vítimas politraumatizadas que geraram ficha de atendimento pelas Unidades de Suporte Básico e Avançado do SAMU de Teresina- PI no ano de 2009. Foram excluídas as fichas de atendimento de outros tipos de acidentes, pacientes com diagnóstico de politrauma que não foram vítimas de acidentes motociclísticos ou que tiveram remoção antecipada.

Para a coleta de informações procedeu-se à consulta manual de todas as fichas de atendimento diário de 2009 e foram selecionadas aquelas que se adequaram aos critérios de inclusão, cujas informações foram transcritas para o instrumento específico elaborado pelos pesquisadores. Esse procedimento ocorreu nos meses de agosto e setembro de 2010.

Após a etapa descrita, procedeu-se à análise dos dados por meio de estatística descritiva simples cujos resultados foram apresentados em forma de tabelas e gráficos, para melhor visualização e compreensão. Para tal, utilizou-se o software Microsoft Excel XP.

A pesquisa obedeceu aos critérios da resolução do ConseIho Nacional de Saúde (CNS) 196/96, que garante sigilo em relação às informações coletadas, bem como o anonimato dos participantes. Foi devidamente aprovada pelo Comitê de Ética e Pesquisa - CEP da Faculdade Integral Diferencial - FACID (protocolo $n^{\circ} 410 / 09$ ) e autorizada pela Fundação Municipal de Saúde de Teresina.

\section{RESULTADOS}

Finda a coleta de dados, constatou-se que, dos 4.541 atendimentos realizados pelo SAMU a vítimas de trauma por acidentes de trânsito, 3.829 foram por acidentes motociclísticos, o que perfaz $84 \%$ das causas dos atendimentos.

No que se refere ao gênero, o sexo masculino teve ampla prevalência, com um total de 2.915 vítimas (76,13\%) em comparação com o total de vítimas do sexo feminino, que foi de $893(23,3 \%)$. As fichas de atendimento que não tiveram a identificação do gênero somam 22 (0,57\%). Grande parte das vítimas são adolescentes e adultos, já que os casos se concentraram na faixa etária de 11 a 40 anos. Isso constitui percentual de $77 \%$. 


\section{Faixa Etária}

\section{0}

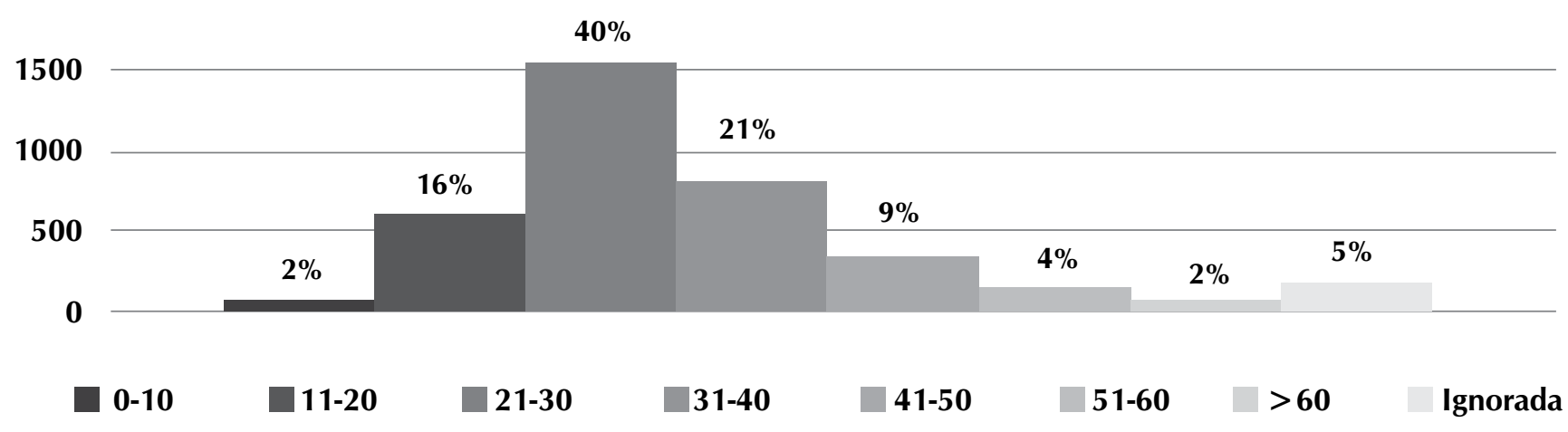

Gráfico 1 - Faixa etária das vítimas de acidentes motociclísticos atendidos pelo SAMU no ano de 2009. Teresina-PI, 2010.

Quanto à distribuição das vítimas segundo o dia da semana apresentada na tabela 1 , verificam-se mais registros aos finais de semana, os quais se podem descrever assim: aos domingos 955 casos (25\%); aos sábados $779(20 \%)$; às sextas-feiras $518(14 \%)$.

Tabela 1 - Distribuição das vítimas de acidente motociclístico atendidas pelo SAMU no ano de 2009, segundo o dia da semana. Teresina-PI, 2010.

\begin{tabular}{lcc}
\hline DIA DA SEMANA & N & \% \\
\hline Domingo & 955 & 25 \\
Segunda & 482 & 12 \\
Terça & 352 & 9 \\
Quarta & 367 & 10 \\
Quinta & 376 & 10 \\
Sexta & 518 & 14 \\
Sábado & 779 & 20 \\
\hline TOTAL & 3829 & 100 \\
\hline
\end{tabular}

Em relação ao horário do acidente, destacou-se o período noturno, com $1.218(32 \%)$ vítimas, seguido do horário vespertino com $1.123(29 \%)$. O horário da manhã e o da madrugada totalizaram, juntos, 39\% dos acidentes (Gráfico 2).

\section{Horário}
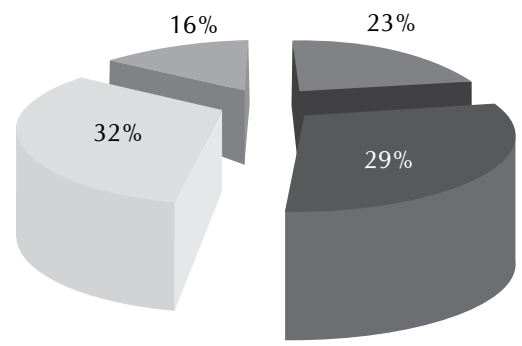

07:00 às $12: 59$

$13: 00$ às $18: 59$

19:00 às 00:59

01:00 às 06:00

Gráfico 2 - Percentual de vítimas segundo o horário da ocorrência de acidentes motociclísticos. Teresina-PI, 2010.
Os mecanismos do trauma mais frequentes foram queda $(58 \%)$ e colisão moto-carro (23\%), como mostra a Tabela 2.

Tabela 2 - Distribuição das vítimas de acidente motociclístico atendidas pelo SAMU no ano de 2009, segundo o tipo de acidente. Teresina-PI, 2010.

\begin{tabular}{lcc}
\hline TIPO DE ACIDENTE & $\mathbf{N}$ & $\mathbf{\%}$ \\
\hline Queda & 2.220 & 58 \\
Carro & 865 & 23 \\
Bicicleta & 204 & 5 \\
Pedestre & 177 & 5 \\
Ônibus & 51 & 1 \\
Caminhão & 22 & 1 \\
Objeto Fixo & 29 & 1 \\
Moto/Moto & 226 & 6 \\
Animal & 33 & 1 \\
Metrô & 2 & 0 \\
\hline TOTAL & $\mathbf{3 . 8 2 9}$ & $\mathbf{1 0 0}$ \\
\hline
\end{tabular}

Quanto às regiões corpóreas mais afetadas nos acidentes motobilísticos, pode-se observar no Gráfico 3 maior frequência de acometimento nos Membros Inferiores (MMII) com 1.055 (36\%) vítimas, seguida dos Membros Superiores (MMSS) com 651 (23\%), face com 533 (18\%), Trauma Crânio-Encefálico (TCE) 367 (13\%).

Os resultados apontam que, dos 3.829 politraumatizados por acidente motociclístico, apenas $2.511(65,57 \%)$ faziam uso do capacete no momento do agravo. Além disso, $447(12 \%)$ vítimas referiram ingestão de álcool ou estarem alcoolizadas ao se acidentarem. A maior proporção de vítimas politraumatizadas por acidentes motociclísticos que necessitaram de atendimento pelo SAMU ocorreu no mês de dezembro com $406(10,6 \%)$ casos. A coleta de dados possibilitou também a análise da ocorrência ou não de óbitos, sendo que o coeficiente médio de mortalidade imediata foi de $1 \%$. 


\section{Região Corpórea}

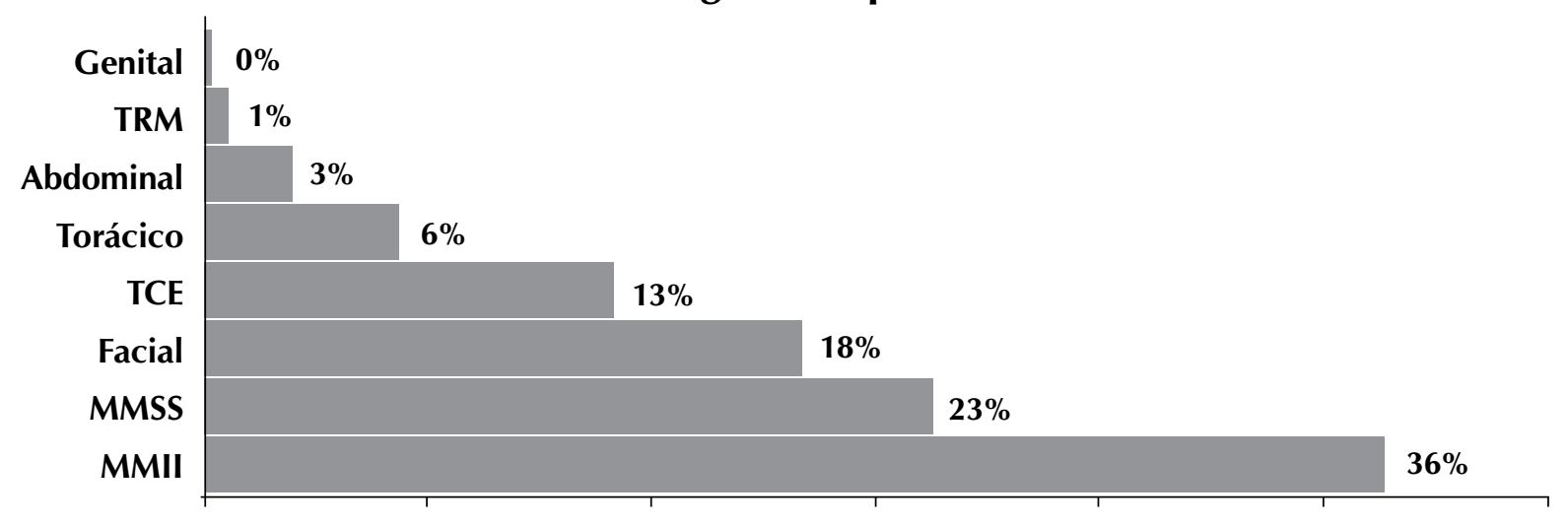

Gráfico 3 - Distribuição das regiões corpóreas mais afetadas nas vítimas de acidentes motociclísticos. Teresina-PI, 2010.

\section{DISCUSSÃO}

Para uma visão global da magnitude do problema, apresenta-se, inicialmente, uma análise comparativa entre as vítimas de acidentes de moto e as dos demais veículos a motor. Verifica-se com isso um número de vítimas por acidentes de moto proporcionalmente maior do que o número de vítimas dos demais veículos. Algumas pesquisas corroboram este estudo ao apontarem os usuários de moto como a principal vítima no trânsito em nosso país ${ }^{(8-9)}$. Isto é reflexo do número de motos em circulação, da desorganização do trânsito, da deficiência geral da fiscalização, do comportamento dos usuários e da impunidade dos infratores ${ }^{(10)}$.

Na pesquisa ora realizada, pôde-se constatar que as vítimas são predominantemente do sexo masculino. Essa, tudo indica, parece ser uma característica comum às ocorrências nas grandes cidades. Em Fortaleza, por exemplo, essa predominância foi superior a $98 \%^{(11)}$. É notório o maior número de motociclistas do sexo masculino. Além disso, o comportamento mais agressivo desse grupo no trânsito expõe os motociclistas a maiores riscos na condução dos veículos, como velocidade excessiva, manobras mais arriscadas e consumo de álcool ${ }^{(12)}$.

Fazendo uma apreciação do que o gráfico 1 revela, constata-se que a faixa etária de 21 a 30 anos apresenta uma predominância de $40 \%$ em relação às demais idades. Dados semelhantes foram identificados nos estados de São Paulo(13), Goiás $^{(14)}$ e Mato Grosso ${ }^{(9)}$. A constatação evidencia que essa realidade se deve à inexperiência, à impulsividade, ao prazer em experimentar sensações de risco, à autoconfiança na condução do veículo, além de excesso de velocidade e desrespeito às normas de segurança ${ }^{(15)}$. O predomínio de adultos jovens nessas ocorrências produz impacto significativo (e negativo!) na economia do estado, por atingir pessoas em plena idade produtiva.

Em reforço dos resultados dos estudos realizados em Sergipe $^{(12)}$ e Minas Gerais ${ }^{(16)}$, a presente investigação constatou ainda que os acidentes nos finais de semana superam os acontecidos em dias úteis da semana. Atribui-se esse fato ao grande número de eventos festivos, ingestão de bebida alcoólica mais frequente, ultrapassagem do limite de velocidade, manobras arriscadas e diminuição da fiscalização nesses dias.

O período noturno, no Pará, configura-se como o horário em que ocorre a maioria dos acidentes ${ }^{(1)}$. Isso se associa ao cansaço do fim do dia, à elevação do fluxo de veículos, à variação da visibilidade limitada pelo alcance dos faróis, a veículos não sinalizados, à menor fiscalização da polícia, ao desrespeito à sinalização, ao excesso de velocidade e ao uso de álcool ou drogas ${ }^{(15,12)}$.

Além disso, verifica-se que a queda e a colisão moto-carro são os tipos de acidentes mais frequentes. Isso corrobora com estudos realizados recentemente em Natal- $R N^{(17)}$ e Aracaju$-\mathrm{SE}^{(18)}$, em que se destaca a queda como responsável pelo maior número de vítimas, seguida da colisão moto-carro. Disso tem resultado traumatismos em diversas partes do corpo.

Para os motociclistas, os segmentos corpóreos mais acometidos por traumas foram os MMII, MMSS e cabeça. Estudos ${ }^{(19-20)}$ também evidenciam os MMII $(53,9 \%)$, MMSS $(41,1 \%)$, e segmento cefálico $(3,1 \%)$ como as áreas mais afetadas. Tais dados confirmam a presença frequente, e em conjunto, desses traumas; porém, as ocorrências evidenciadas em MMII são as maiores causas de morbidade, por serem justamente as regiões mais desprotegidas. A alta letalidade, entretanto, está diretamente relacionada aos traumatismos cranioencefálicos, preveníveis pela utilização do capacete.

O uso do capacete é requisito essencial e obrigatório para condução de motocicletas. No entanto, ficou evidente o elevado percentual de condutores que não o utilizavam no momento do acidente, apesar de essa atitude se constituir em infração gravíssima, segundo o Artigo 244 do Código Nacional de Trânsito, tendo como penalidade multa e suspensão do direito de dirigir ${ }^{(21)}$.

Analisando os dados quanto ao uso de bebida alcoólica, pesquisas apontam uma forte relação entre a ingestão de álcool e AT, uma vez que a bebida gera uma sensação de confiança nos condutores de veículos a motor, porém produz perda nas suas habilidades de tempo de reação e coordenação ${ }^{(13)}$. Constatou-se, por exemplo, no Rio de Janeiro ${ }^{(22)}$, que $70 \%$ dos 
AT's causados pelo consumo de bebidas alcoólicas tendem a ser bastante violentos,com óbito de condutores e passageiros.

O mês de dezembro foi o de maiores índices de acidentes motociclísticos, talvez por ser período de maior movimentação no trânsito em decorrência da finalização do ano e das festividades. Investigação realizada no Mato Grosso do Sul (23) também identificou dezembro como o mês de maior número de vítimas, pelo alto fluxo e movimentação de pessoas em virtude das férias escolares.

No que tange à ocorrência de vítimas com óbito, os dados revelaram percentual de $1 \%$, semelhante a estudo realizado em Sorocaba-SP(24). Analisando a relação entre feridos e mortos, encontrou-se uma relação de 174:1. Isso evidencia que os índices de morbidade são e devem ser mais preocupantes.

\section{CONSIDERAÇÕES FINAIS}

Entre as vítimas investigadas prevaleceram jovens, do sexo masculino, na faixa etária de 21 a 30 anos. Quanto ao tipo de acidente, verificou-se que a maioria foi por queda. $\mathrm{O}$ horário noturno e a zona urbana tiveram a maior concentração. Destacou-se o final de semana, sobretudo o domingo como o dia de maior ocorrência. No mês de dezembro, gerou-se o maior número de registros de casos, sendo o trauma musculoesquelético o mais evidenciado nesses eventos. Obteve-se um número significativo quanto à não utilização de EPIs, como, também, quanto à ingestão de bebida alcoólica pelos motociclistas. Constatou-se ademais que o óbito imediato teve um percentual mínimo, resultado oposto, quando comparado à morbidade decorrente desse tipo de acidente.

Conhecer a população envolvida e as circunstâncias em que esses acidentes aconteceram possibilitou detectar que o comportamento humano se constitui numa das principais causas desse tipo de agravo, sendo, pois, passível de modificação por meio de intervenções preventivas.

Percebe-se que há necessidade de um trabalho de conscientização voltado para a sociedade em geral, mas, principalmente, para as pessoas reconhecidamente usuárias desse tipo de transporte. Torna-se, portanto, imprescindível e imediata a adoção de medidas socioeducativas que garantam o comportamento adequado dos indivíduos no trânsito, visando à redução e prevenção dos acidentes. Espera-se que os resultados possam estimular e subsidiar pesquisas futuras nessa área, uma vez que a continuação de estudos que abordem essa temática contribuirá com a formulação de estratégias de enfrentamento desse agravo.

\section{REFERÊNCIAS}

1. Macêdo DWM, Oliveira FPA. Epidemiologia de acidentes urbanos com atendimento móvel de urgência, Santarém, PA, maio a setembro de 2009. Rev Saúde Desenvolv 2012;1(1):107-26.

2. Calil AM, Sallum EA, Domingues CA, Nogueira LS. Mapeamento das lesões em vítimas de acidentes de trânsito: revisão sistemática da literatura. Rev Latino-Am Enfermagem 2009;17(1):121-7.

3. Almeida AC. Avaliação da implantação e do desenvolvimento do sistema público municipal de atendimento pré-hospitalar móvel da cidade de Recife. Recife. Dissertação [Mestrado em Saúde pública] -Fundação Oswaldo Cruz; 2007.

4. Mascarenhas MDM, Pedrosa AAG. Atendimento de emergência por violência em serviços públicos de Teresina-PI. Rev Bras Enferm 2008;61(4):493-9.

5. Martins CBG. Acidentes na infância e adolescência: uma revisão bibliográfica. Rev Bras Enferm 2006; 59(3):344-8.

6. Appolinário F. Dicionário de metodologia científica: um guia para a produção do conhecimento científico. São Paulo: Atlas; 2009.

7. Creswell J.W. Projeto de pesquisa: métodos qualitativo, quantitativo e misto. Tradução Luciana de Oliveira da Rocha. 2. ed. Porto Alegre: Artmed; 2007.

8. Caixeta CR, Minamisava R, Oliveira LMAC, Brasil VV. Morbidade por acidentes de transporte entre jovens de Goiânia, Goiás. Ciência Saúde Coletiva 2010;15(4):2075-84.

9. Filho CARS, Reis ES, Barros IGP. Perfil dos pacientes vítimas de acidente de trânsito atendidos na clínica de fisioterapia da Unic no ano de 2005 a 2008. Rev UNICiências 2010;14(1):83-94.

10. Freire E. Trauma: a doença dos séculos. São Paulo: Atheneu; 2001.

11. Andrade LM, Lima MA, Silva CHC, Caetano JA. Acidentes de motocicleta: características das vítimas e dos acidentes em hospital de Fortaleza-CE, Brasil. Rev RENE 2009;10(4):52-9.

12. Vieira RCA, Hora EC, Oliveira DV, Vaez AC. Levantamento epidemiológico dos acidentes motociclísticos atendidos em um Centro de Referência ao Trauma de Sergipe. Rev Esc Enferm USP 2011;45(6):1359-63.

13. Duailibi S, Pinsky I, Laranjeira R. Prevalência do beber e dirigir em Diadema, estado de São Paulo. Rev Saúde Pública 2007;41(6):1058-61.

14. Sado MJ, Morais FD, Viana FP. Caracterização das vítimas por acidentes motociclísticos internadas no hospital de urgência de Goiânia. Rev Movimenta 2009;2(2):49-53.

15. Brasileiro BF, Vieira JM, Silveira CES. Avaliação de traumatismos faciais por acidentes motociclísticos em Aracaju-SE. Rev Cir Traumatol Buco-Maxilo-fac 2010;10(2):97-104.

16. Chavaglia SRR, Amaral EMS, Barbosa MH, Bittar DB, Ferreira PM. Vítimas de trauma por causas externas na cidade de Uberaba-MG. Mundo Saúde 2008;32(1):100-6.

17. Barros WCTS. Avaliação da gravidade do trauma em condutores de motocicleta vítimas de acidentes de trânsito no Rio Grande do Norte. Natal. Dissertação [Mestrado em Enfermagem]- Universidade Federal do Rio Grande do Norte; 2008. 
18. Brasileiro BF, Vieira JM, Silveira CES. Avaliação de traumatismos faciais por acidentes motociclísticos em Aracaju/SE. Rev Cir Traumatol Buco-Maxilo-fac 2010;10(2):97-104.

19. Debieux P, Chertman C, Mansur NSB, Dobashi E, Fernandes HJA. Lesões do Aparelho locomotor nos Acidentes com motocicleta. Acta Ortop Bras 2010;18(6):353-6.

20. Silva LA, Martins JT, Freitas FCT, Dalri RCMB, Robazzi MLCC. Algumas características do trabalho e do trabalhador mototaxista: revisão bibliográfica. Rev Enferm UFPE 2009;3(3):246-55.

21. DENATRAN. Código de Trânsito Brasileiro: instituído pela Lei $n^{\circ}$ 9.503, de 23 de setembro de 1997. 3 ed.
Brasília: DENATRAN; 2008.

22. Abreu AMM, Lima JMB, Silva LM. Níveis de alcoolemia e mortalidade por acidentes de trânsito na cidade do Rio de Janeiro. Esc Anna Nery Rev Enferm 2007;11(4):575-80.

23. Ganne N. Estudo sobre acidentes de trânsito envolvendo motocicletas na Cidade de Corumbá e região, Estado do Mato Grosso do Sul, Brasil, no ano de 2007. Rev Pan-Amaz Saúde 2010;1(3):19-24.

24. Rodrigues NB, Gimenes CM, Lopes CM, Rodrigues JMS. Mortes, lesões e padrão das vítimas em acidentes de trânsito com ciclomotores no município de Sorocaba, São Paulo, Brasil. Rev Fac Ciênc Méd Sorocaba 2010;12(3):21-5. 